\title{
Development of alternative interpretations: The story of an orphaned boy affected by HIV and AIDS and father abandonment
}

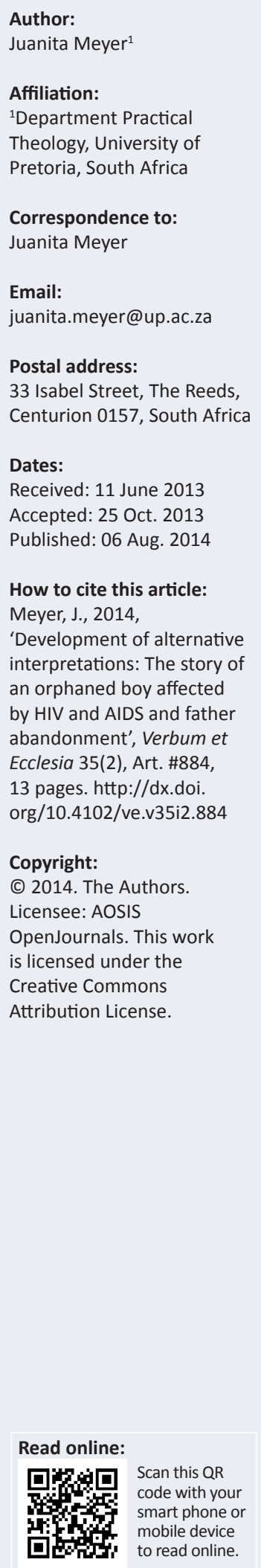

This article elaborated specifically on the research journey in arriving at the development of an alternative narrative, which points beyond the local community, with reference to a broader study which aimed at addressing uncertainties about the type and nature of the relationship between HIV and AIDS and adolescent male orphans affected by this disease and all its aspects, such as poverty, exposure to crime and stigmatisation and lack in parental figures, more specifically the lack of the father figure. Subsequently, this study aimed at dissecting the orphan's life experiences in the midst of HIV and AIDS and how these experiences will influence his sexual and power relations with women and his role as future father and husband, in the absence of a father figure. The researcher wanted to explore ways in which these past and future narratives influence or affect the male orphan's view of and relationship with God and assess whether it is it just this view of and relationship with God that influence and affect his relationship with his past narrative and writing of his future narratives. This article described and explained the research process as it utilised the epistemological viewpoints of a postfoundational notion of practical theology and the methodological tools of the seven movements of a postfoundational practical theology. With the use of the metaphor of Tree of Life and the David narrative, the researcher journeyed with the co-researchers (i.e. the children who took part in this research) in the construction of a preferred alternative narrative, which, in turn, functions as a guiding metaphor, for aspiring to the future and living their lives in a preferred and satisfying manner. This article concluded with an alternative narrative as developed by one of the co-researchers, as an example of how these theoretical viewpoints can be used in praxis in developing alternative narratives which frees the persons from the constraints of a problem-saturated narrative, with special reference and acknowledgement to Professor Julian Müller, who introduced the researcher to the world of possibilities.

\section{Introduction}

It is in the reading of several studies regarding HIV and AIDS in South Africa, that it was noticed that many of these studies focus on the plight of specifically women affected and infected by HIV and AIDS. The researcher then wondered about the position of the African man in the narrative of HIV and AIDS and the various factors that exacerbate the spreading and subsequent consequences of this disease. It was noticed that whilst the world is overtly making an effort to study women and the ways they are exploited and abused, it is at the same time ignoring or perhaps missing men's active role in this scenario. Discussions around women and marriage, women and sexual exploitation, women and abandonment, women and lower social status, are explicitly implying men's very active role in these activities.

Orphaning as a result of the HIV and AIDS deaths of parents as a national trend has been documented as a consequence left in the wake of this disease. The Joint United Nations Programme on HIV and AIDS (UNAIDS) (2010:112) states that the global number of orphans that have resulted from HIV and AIDS deaths has increased from 14.6 million in 2005, to 16.6 million in 2009 , of which $90 \%$ live in sub-Saharan Africa. Further investigation led to the discovery that the context of HIV and AIDS is infiltrated by various factors that exacerbate the spread of HIV and, at the same time, maintain various stereotyping and social prejudices that worsen the effects of HIV and AIDS. Some of these factors are poverty and rampant gender inequalities, exposure to crime and a lack of parental figures in guiding children into adulthood. As a result of this investigation, it became clear that another crisis emerges from this context. This crisis is one of fatherlessness, which seems to define a major portion of the South African population. Tebogo Monama of The Sowetan (2012:n.p.) states that, 'Between 1996 and 2010 the proportion of children in South Africa whose fathers had died, increased by $75 \%$.' He goes on to say that more worrying is the increase of 5\% from 1996 to 2010, in absent, but living fathers, leaving almost half of all South African children without a father figure (cf. Holborn \& Eddy 2011:4; Monama 2012). 
Based on the above information, this research investigated the relationship between HIV and AIDS and adolescent male orphans affected by this disease and all its aspects, such as poverty, exposure to crime and stigmatisation and the lack of the father figure. The research aimed at dissecting the orphan's life experiences in the midst of HIV and AIDS and how these experiences influence his sexual and power relations with women and his role as future father and husband, in the absence of a father figure. These aspects are investigated with the use of the postfoundational notion of practical theology, the model of narrative as theoretical framework and the seven movements of practical theology as methodology.

As a result of using the narrative approach and the seven movements of practical theology, several sequential narratives were attained from the co-researchers ${ }^{1}$ of this study. Sequential here refers to the narratives as they progressed in development from journeying from movement one to movement seven in the seven movements of practical theology, starting with a problem-saturated narrative and moving to the development of an alternative narrative, which liberates the co-researcher from the confinement of a narrowly (thinly) defined future narrative. The outcome of such a sequential, albeit circular, movement is the development of an alternative narrative that points beyond the local community.

This article elaborates specifically on the research journey in developing such an alternative narrative, based on the alternative narrative of one of the co-researchers, given in this article as an example of how the postfoundational notion of practical theology and the seven movements of practical theology can be used in developing alternative narratives in practice. The aim of the article is to bring tribute to Julian Müller and the work he has accomplished in the field of practical theology and pastoral family therapy, by explaining how the seven movements of a postfoundational notion of practical theology can be utilised in praxis. More than often theory remains just that - theory. Müller (2005:78-79) adamantly states that a postfoundational notion of practical theology can only be useful as it moves from theory to praxis and from praxis back to theory. With this, Müller emphasises the contextual imperative of practical theology. Browning (1991:34) refers to this movement as 'the circle of practical wisdom'. Müller (2005:78) states that practical theology is indeed, '... only possible as contextual Practical Theology'; otherwise, it runs the danger of regressing into a type of systematic theology (cf. Willows \& Swinton 2000:42). With this in mind, this article advocates for a practical theology that is always locally contextual, socially constructed, directed by tradition and exploring interdisciplinary meaning (cf. Müller 2005:78).

1.The term 'co-researchers' was chosen to refer to the children who were the subjects of the study. 'Co-researchers' is preferred over 'subjects', as it indicates a participatory and subjective process, where the researcher joins these children a participatory and subjective process, where the researcher joins these children
on their journey of discovery. They are not the 'objects' of study, their insights and on their journey of discovery. They are not the 'objects' of study, their insights
subjective experiences are valued, as are the experiences of the researcher.

\section{Epistemology and research method}

In arriving at these aims, and in staying true to the very personal nature of these narratives, research methods from the qualitative research design and, more specifically, from the theoretical viewpoints of a postfoundational notion of practical theology and narrative therapy, were utilised in exploring the above issues and in developing alternative narratives. The research process is as important as the development of the narrative itself, as it provides liberating avenues in staying true to the subjective nature of these experiences.

A brief overview of the postfoundational notion and associated seven movements of a postfoundational notion of practical theological, as it was used during this study in arriving at an alternative narrative, will now be provided. For an overview of the metaphor of the narrative, narrative therapeutic tools and the use of metaphors in narrative research, refer to the article written by Loubser and Müller (2011).

\section{A postfoundational notion of practical theology}

Inherent to this study's epistemology and methodology are the paradigms of practical theology and, more specifically, a postfoundational notion of practical theology. Gerkin (1991:13) states that practical theological inquiry is concerned with both theological concerns as well as practical considerations. This means that through the imperatives of practical theology, we are interested in serving people and their concerns through their daily communications and relations within a specific cultural and social setting, by showing continuity between the story of the Bible and the story of the particular person at a particular place within a particular point in time.

Practical theology therefore aims at acting within the paradigm of the social world, through the paradigm of Christian theology, traditions and language; thereby closing the 'gap' between a person's day-to-day experiences and concerns and his or her religious experiences, which are often seen as distinctly different. Practical theology aims at addressing specific ambivalent or paradox social issues through not only the Word of God, but by also encouraging and emphasising the imperative of action; hence, it is the logos through, within and by praxis. Practical theology is, in essence, propelled by elements of liberation, justice and reinstating human dignity.

Pattison (2000:42) states that practical theology is an enterprise, which gives special attention to specific situations and is therefore known '... for the delicacy of its distinctions, not the sweep of its abstractions'. He continues to say that practical theology emphasises the seeing and understanding, first listening and then carefully speaking; it is sensitive to context and situation and therefore is modest in its claims and postulations (cf. Pattison 2000:42).

As mentioned before, Müller (2005:78) emphasises the contextual imperative of practical theology by stating that the 
understanding of a specific context is central to the practice of practical theology. It cannot function in a general universal context as the very essence thereof is to be focused on specific, localised and concrete contexts (cf. Müller 2005:78; Willows \& Swinton 2000:42). Within this context it becomes important to first listen to the narratives of people who are struggling with real life issues. After listening, a description of the context has to be made. Note that a general description of the context will not do - the description must be relevant and applicable to the person's specific and concrete situation. Müller (2005:78-79) states that practical theological actions should not only be truthful to the specific localised context, but also within the methodology utilised to understand the dynamics within such a context - such a methodology must always be purposeful in its circular movement by moving from theory to context, back to theory and again, back to praxis (context).

In addition to its circular movement, practical theology also functions on various levels - it can be formal or informal, practical or academic. Müller (2005) states:

It can be very spontaneous, informal and local. It can also be very formal, systematic and organised. It can be part of ministerial activities on the congregational level, or it can be highly academic on university level. (p. 73)

Whatever level practical theology functions in and on, it must always be driven by the lyrics of locality, embeddedness and situatedness (cf. Müller 2005:73). This context contains four specific actions, which prompt the 'mission' of practical theology: 'Practical theology happens whenever and wherever there is a reflection on practice, from the perspective of the experience of the presence of God' (Müller 2005:73). Thus, embedded within the locus of practical theology, are four insistencies, namely: reflection, perspective, experience and presence. These actions indicate that practical theology can never be detached from the '... basic forms of theological reflection' (Müller 2005:73-74).

The above statements illustrate the importance of integrating the model of transversal reasoning into the philosophy and subsequent methodology of the discipline of practical theology. Transversal rationality is a term which refers to the postfoundational notion of rationality, which assumes that true rational conversation is only possible through interdisciplinary action and movement beyond one's own embedded and local context to a cross-cultural space in time. Van Huyssteen (1999) states that:

Transversal rationality thus emerges as a place in time and space where our multiple beliefs and practices, our habits of thought and attitudes, our prejudices and assessments, converge, the texture of this transversality, thus resides in the domain of our social, communal and institutional practices. (p. 136)

Transversality motivates us to move between the two polarities of Modernism and Postmodernism, so that we can find a space and a place in time where we can engage in a rational manner, with our interpreted experiences and communicated praxes, which will eventually bring us to a satisfactory point in time where we can communicate and articulate praxis critique, give historical judgements and make assessment to arrive at a narrative of disclosure. The advantage of this method of rationality is that at the end of the journey we do not find ourselves in an empty space of universalism or globalism; or at a place which is built on faltering and endlessly pluralistic foundations, or even at a place with no foundations and relative concept of reality (cf. Van Huyssteen 1999:139). Transversal rationality:

... creates a safe space where our different discourses and actions are seen at times to link up with one another, and at times to contrast or conflict with one another. (Van Huyssteen 1999:139)

It takes us to a place where we can engage in conversation so that we can come to an intelligible, responsible, liberated and just understanding.

Reflection has always been part of the episteme of practical theology; however, through the emergence of postfoundationalism and, more specifically, the notion of transversality, we are now provided not only with a paradigm or a model, but also a method which ensures that both reflection and continuous evaluation of our own episteme becomes the imperative of practical theology.

By adding the notion of postfoundational rationality to the practice of practical theology, a rediscovery of the basic and most simple imperatives of practical theology is constituted (cf. Müller 2005:73-75). Müller (2005:80) states that the postfoundational notion of rationality helps us to also better position ourselves within a theological world (cf. Van Huyssteen 1997:180-192), because it takes the movement of practice-theory-practice seriously, thereby bringing the model into operation. The postfoundational notion of rationality does not only influence practical theology's philosophy, but also its methodology: 'This practical theological narrative is not only a paradigm-story, but also a method-story' (Müller 2005:86). If this philosophy does not eventually move into methodology, it will contradict the imperatives of the model. Therefore, a postfoundational notion of rationality provides us with an integrative narrative, which includes the theologian in both processes of 'story-telling' and 'story-making' (cf. Müller 2005:86). This participation should be very sensitive and descriptive in the deconstruction of problematic discourses, as well as in its development of alternative narratives (cf. Müller 2005:86). With the use of this paradigm, a prerequisite before moving into method would be to attain a certain attitude of sensitivity and discretion, as well as openness to the context and being unbiased so that specific cues of discourse can be heard.

This type of theological reflection or attitude, circles around three specific movements (cf. Van Huyssteen 2004). Firstly, an acknowledgement of contextuality, the role of interpreted experiences and the influence of disciplinary tradition in the values people hold and how these values are used to reflect 
upon God and his presence in the world (cf. Müller 2005:7677). Secondly, an increased awareness of an epistemic duty, which extends the boundaries of and our boundedness to our specific discipline, community, groups, cultures et cetera, so that we can partake in a reflective and effective interdisciplinary discussion, whereupon shared resources can be discovered (cf. Müller 2005:76-77; Van Huyssteen 1999). Finally, these newly discovered shared resources could be expressed most effectively with the use of the notion of transversality, as it creates new possibilities for discussion through the imperatives of reflection and action, whilst, at the same time, keeping us humble in our endeavours as we gain new respect for various and diverse reasoning strategies (cf. Müller 2005:77; Schrag 1992:148ff.; Welsch 1998:764ff.). It guides us by keeping us concrete, local and contextual whilst reminding us of how our episteme are shaped by tradition (cf. Müller 2005:77).

\section{Methodology for research: The seven movements of a postfoundational notion of practical theology}

Four requirements of a postfoundational notion of practical theology have been developed:

- the context and interpreted experiences

- traditions of interpretations

- a reflection on God's presence

- movement beyond the local.

These four requirements correspond to the four specific missional actions of practical theology, which are embedded within the locus of practical theology - mentioned before namely: reflection, perspective, experience and presence. Furthermore, these requirements have been extended into seven movements that guide the specific methodological actions of the researcher and the co-researchers in exploring, describing and constructing narratives.

These four requirements will now be described and explained as used in collaboration with the epistemological paradigms of the narrative model and of the cultural-linguistic model of George Lindbeck (1984), as applied in this research. The specific metaphors that were used in assisting the coresearchers in describing their context and in developing alternative narratives will be briefly explained.

\section{The context and interpreted experiences}

The first requirement for a postfoundationalist practical theology refers to being locally contextual and entails the context and interpreted experiences within that context. Three movements were developed in directing the exploration of interpreted experiences:

- A specific context is described.

- In-context experiences are listened to and described.

- Interpretations of experiences are made, described and developed in collaboration with co-researchers.
These movements, as part of the first requirement, aim specifically to describe the context and related experiences, understand experiences through active listening and questioning and, finally, interpret these experiences from the perspectives of the co-researchers. These movements are supported by the imperative of the postfoundational notion of reality, to first listen to the stories of people in real-life situations, before a description of context can be attempted and before interpretations can be made.

In attaining the abovementioned aims, empirical research was done with the use of the methods proposed by the narrative model and more specifically by using the metaphor of Tree of Life. This metaphor used sub-metaphors, such as the 'roots', 'trunk', 'branches', 'leaves' and 'bugs', to indicate specific life events and significant people. Added to this metaphor was the 'ground' in which trees are tightly and safely grounded. The roots indicated the familial history of the children's lives, their place of birth and their ancestors. The ground, in which a tree grows out of, and in which it is tightly grounded, refers to the 'nutrients' a tree receives from the earth - the mineralfilled soil that makes it grow. Therefore the ground refers metaphorically to one's spirituality, one story of createdness or to one's experiences with or of God's involvement in one's life. The trunk of a tree refers to one's skills and abilities, or one's talents. The branches in turn refer to one's hopes and dreams that entail endless possibilities and can 'reach up to the sky'. The leaves refer to the people in one's life, living or deceased - this metaphor can be described in more detail by stating that the green leaves refer to significant people who are still alive, whilst the withered leaves refer to those significant people whom one has lost, through death or another form of loss. The 'fruits' or 'blossoms' of a tree, in turn, refer to the things or gifts we have received from other people, such as love or kindness, whilst the bugs refer to those people who have not been kind to us. Finally, a reference was made to the 'storms' trees experience, which symbolise the difficult times we as people also experience, such as death, illness, abandonment or poverty.

The co-researchers engaged actively with this metaphor during group sessions at a three-day camp held in Magaliesburg, 10-12 October 2008. The theme of the camp was the Tree of Life and the aim was to establish rapport with the children and to explore the context in which the children find themselves. The primary outcome of the camp was to find closure regarding the 'storms' they experienced and commemorate the significant people they have lost in their lives. The camp ended with a celebration of the skills they have acquired in overcoming their problems and the courage they found to re-write their future narratives in such a way that it liberated them from the events and people who constrain the development of their full potential. The sessions commenced by first discussing the metaphor of a Tree of Life and its accompanied sub-metaphors. The children were then asked to draw their own trees of life, by including all the sub-metaphors, except the storms (that was discussed during later sessions). It was pertinently stated that the children could include anything else they feel significant 
or meaningful to their story, thereby creating a space where they could use their own creativity and elaborate on their experiences metaphorically. Afterwards, everyone had an opportunity to discuss his or her Tree of Life. The activities around the Tree of Life metaphor assisted in the description and elaboration of the specific context(s) in which the children found themselves and subsequent experiences of significant events.

After these discussions, the group sessions progressed into movements two and three of the seven movements of practical theology, which entail the listening to and description of in-context experiences and describing and developing interpretations of experiences, in collaboration with co-researchers. Thrift and Amundson (2007:44) emphasise the importance of experiences and the meaning of these experiences embedded within specific contexts by stating that all experiences and all constructed meanings are embedded in context and the person's relation with that context: 'Although human beings actively work to make sense and ascribe meaning to their lives, this always, happens within the confines of history and culture.'

At this stage of the research process, it became important to verbalise and conceptualise specific experiences and the meaning that was created from these experiences, embedded within the co-researchers' specific context. Again, the Tree of Life metaphor was used in assisting the co-researchers to elaborate on the events and people who had a significant influence on the development of their current narratives. The sub-metaphors of storms and bugs were used to mine for such experiences and interpretations. The metaphor of storms in this context indicated that every tree faces some type of storm in its lifetime and is damaged by the storm in some way; however, because trees usually stand in a forest, they can protect each other from the worst blows of the storms. One of the children responded to his experience of storms by stating how 'every cloud has a silver lining'. By this he meant that the storms do not last forever. After this discussion, everyone placed their drawing of their trees on a wall - this assisted in displaying all the trees on one wall, which then looked like a forest of trees and not only a single one standing on its own. Subsequently, this indicated that although we are individuals and experience our own individual storms, we support each other by standing together and being stronger as a forest of people. Thereafter, everyone also had an opportunity to discuss some storms they had experienced, as well as what talents, skills or abilities they used to combat the effects of the storm. This activity then effectively assisted the children to elaborate on their context and experiences and to delve deeper into the meaning of the narratives created from these experiences.

Additionally, the metaphor of the biblical David was used in encouraging a discussion regarding similar or dissimilar experiences between specific events, with the hope of deriving some meaning from our real-life experiences against the background of the experiences of biblical figures. This activity is motivated by Gerkin (1991) and Lindbeck
(1984), who encourage the community of faith to care for its members by offering a narrated context of ultimate meaning, which can serve as a paradigm with which life can be lived. Gerkin (1991:103) states that the community of faith should offer a grammar, a narrative, which can connect people's experiences with the ultimate metaphor of meaning, which is contained in the Christian narrative. Similarly, Lindbeck (1984:32) proposes a model that can be used to do so (this model will be discussed later on).

In the collection of data, the story of David was then used in comparing significant events of his story with those that the co-researchers experienced, thereby closing the gap between the Western and African contextual experience and the experiences of the Christians tradition or the story of God with his people: Gerkin (1991:109) states: 'The Bible is better seen as containing the grounding narrative of a religious community that seeks to structure its life according to the sacred truths contained in that narrative.'

A booklet was created with a series of reading passages regarding various themes found in the David narrative and subsequent introspective questions followed. These reading sections and questions were discussed in group sessions, which stimulated an informal conversation around specific themes of the biblical David. Themes identified from this narrative were the story of how David was chosen by God, despite his many shortcomings, where he defeated the mighty Goliath, where he was tempted by his lust of Bathsheba and subsequently committed murder, where he was challenged by King Saul and, finally, where he at the end of his journey declared: '... all this assembly shall know that the LORD saveth not with sword and spear: for the battle is the LORD'S, and he will give you into our hands' (1 Sm 17:47).

This process and these activities assisted the group to develop and describe interpretations of their own experiences, which correlates with movement three. It is interesting to note that from the discussions around the themes in the David narratives, seven themes were identified as describing the 'Goliath' that the co-researchers were 'fighting'. These themes are also descriptors of the context of the co-researchers. The identified themes were:

- loss and orphanhood

- paternal abandonment

- gender and related sexual norms and stereotypes

- physical, social and emotional poverty

- poor psychosocial development

- the culture of informal settlements

- the involvement of, and engagement with, various nongovernmental and faith-based organisations with this context.

It is important to note that meaning is conveyed through language and, as such, is organised through constructed narratives of meaning. As postmodern researchers, we believe that not only does each interpretation differ, but also that they are equally true and equally valuable (cf. Erikson 
1998:19). Based on this, the co-researchers were provided with an opportunity to re-tell their stories with reference to what it means to them and how they interpret the significant events they came to experience, especially in the light of their current daily experiences and challenges. Various metaphors were used as feedback loops, during to-andfro discussion about and with the text. Therefore, meaning and interpretations were developed and elaborated during constant and continuous dialogue between the given text and the narratives of the co-researchers.

\section{Traditions of interpretations}

The group discussion which sprang out of the discussions regarding the narrative of David assisted the co-researchers to deepen and thicken their self-narratives, as they delved deeper into the various social constructs and grant narratives that assist them in the construction of a self-narrative. This again motivated our search into the traditions of various interpretations - the second requirement and the fourth movement of a postfoundational notion of practical theology. In the description of experiences, it is imperative to consider the various traditions, which inform and shape the interpretations made by the co-researchers.

Working from the assumptions of social constructionism, it became important to attend to the various sociocultural and historical traditions which influence the construction of interpretations of the self-narrative. Social constructionism assumes that specific traditions or discourse in communities inform perceptions and behaviour. In turn, postfoundationalism encourages us to acknowledge the way in which epistemes are also shaped by traditions.

The co-researchers were then guided to reflect on their experiences from the perspectives of their religious and socio-cultural traditions (cf. Demasure \& Müller 2006:418). Open-ended questions and deconstructive questioning (tools specific to the narrative model) were used to elicit such perspectives. Deconstructive listening techniques were used in identifying some of the dominant discourses, which informed both the description and construction of interpretations. We were particularly interested in discourses that influence the construction of the self-narrative in relation to future-related role expectancy and responsibilities, gender identity formation and religious relations, which might or might not influence the spread of HIV and AIDS. Specific themes were identified which might contain such an influence and were subsequently discussed during group sessions. Some of these identified themes were: men's perceptions and expectations of sexual intercourse, their sexual identity, their choice in a partner, their expectations of their partner, their desires towards women and sex, their perceptions regarding their role as breadwinner, as caretaker or protector, their expectations as a husband and father, their perceptions regarding their responsibility as a husband and father, the concept of 'being a real man', their perceptions regarding the religiosity of a 'real man' and his relationship with God, their perceptions regarding physical, emotional and sexual violence and also their perceptions regarding femininity what is expected of a 'real' woman.

In terms of literature, the research did some investigation into identity formation. This is the idea of oneself and how and where one fits into the world. Many theorists refer to this developmental aspect as ego identity and which is an important developmental milestone in the development of the personality that often occurs during late adolescence. The development of an identity indicates the end of childhood and the beginning of adulthood and involves the incorporation and integration of various skills, beliefs and identifications collected as child, into a more coherent whole. The collection of various items, which construe the identity, provide a person with a sense of continuity with his or her past, and direction for the future (cf. Marcia 1993:3).

Additionally, literature research was conducted regarding the familial contexts as experienced by adolescents or children and the influence that this context has on the formation of an identity. Pretorius (2009:57) states that the present nuclear family in South Africa is characterised by four different vulnerabilities:

- Economic vulnerability indicates that unemployment, illness and sometimes death are characteristic of that family and make the family severely dependent on one or two members for financial aid.

- Social vulnerability indicates that there is no social control within a small isolated family, making that family unstable.

- Emotional vulnerability, in turn, indicates that the family members are much dependent on each other for emotional support, which places much pressure on family members who then experience each other's problems much more intensively.

- Pedagogical vulnerability is characteristic of a family who exists of a parent and a child, who build strong relationships so that the child can be guided in becoming an adult (cf. Pretorius 2009:57).

\section{Reflecting on God's presence}

The third requirement of a postfoundational notion of practical theology is to be directed by tradition. This corresponds with the experience of God's presence and is explored in the fifth movement that reflects on the religious and spiritual aspects, especially on God's presence as it is understood and experienced in a specific situation. This movement is the one specific action that distinguishes practical theological research from other types of research in the social sciences. As practical theologians, we aim to close the gap between the story of the individual and the story of God with his people. Gerkin (1991) states that it is necessary to:

... get beneath the level of cognitive or reasonable logic to a level of experience that encompasses the intuitive, the emotional and affective life, and the relational affinities that emerge more from individual and communal living out of a story carried in the person's imagination than they do from intellectual reasoning and/or other logical disputation. (p. 21) 
An important aspect of this research was to connect the stories of the co-researchers to the stories of and about God. Ganzevoort (2012:219) gives a brief outlay of the different approaches to narrative and states that these different approaches centre '... around the question of how human stories and the story of/about God interact' with each other. The central idea in working with narratives in the field of theology and, more specifically, practical theology, is to connect present human experiences with the experiences of the elders in the Bible, in order to gain some understanding of our own experiences. Ganzevoort (2012:21) states that three positions or tendencies can be observed. In the first position, the stories of God express the stories of people - they verbalise what we feel and what we know and this, in turn, validates our own experiences. In the second position, our stories are confronted by the stories of God, thereby critiquing our lives: 'This prophetic style challenges us to reconsider our stories, offering guidance, warning, or comfort' (Ganzevoort 2012:21). Finally, in the third position, we can bring our own stories to the open space provided by the stories of God. We can reflect on our own stories in this space without being forced into one or the other understanding thereof.

Similarly, Gerkin (1991:103) states that a community of faith should serve the purpose of caring for its members by offering a narrated context of ultimate meaning, which can serve as a paradigm with which life can be lived. It should offer a grammar, a narrative, which can connect people's experiences with the ultimate metaphor of meaning that is contained in the Christian narrative (cf. Gerkin 1991:103). George Lindbeck (1984:32) proposes such a model, which he calls the cultural-linguistic model. This model is proposed for pastoral workers in tending to the communities who lost the consensual structure of meaning and value inherent in their stories. This loss of meaning and value results in the loss of one's purpose in life.

This model of doing theology recognises religion as a broad interpretive, often ritualised scheme, which is usually embodied '... in myths or narratives' (Lindbeck 1984:32). Religion, as such a scheme, tends to structure our experiences and our understanding of self and the world that we inhabit. Subsequently, religion corresponds to the concept of culture in its aims of depersonalising its specific culture and its incarnation into narrative and ritual (cf. Gerkin 1991:108). It thereby creates a 'cultural' context which functions and informs in the same way as any other cultural context. Gerkin (1991:108) confirms this by stating that to belong to a specific religion means that one adopts a certain grammar and language and an interpretive frame of reference from which one then understand oneself in relation to one's world. This results in the connection of one's life narrative with the narrative of Christians.

Similarly, Christianity as a religion, expressed through the Bible, is seen as a source which contains the grounding narratives of this religious community, which, in turn, guides people to structure their lives according to these sacred truths that are contained in the narrative of God with his people (cf. Gerkin 1991:109). Christianity therefore functions as a culture in being directive, constructive and meaningful to people in the creation of their life stories. Lindbeck (1984:33) affirms that a religious experience is generally a communal experience. This communal experience is enriched with activities such as ritual and prayer, which continuously remind its members who they are, where they come from and how they can be in the world (cf. Gerkin 1991:110). To add to this, the culture of a religion provides a narrative, which always entails a tension between the past, the present and the future. The activities entailed within a specific religion act as a balancing mechanism of this tension by providing feedback from the past as a guide for future behaviour.

The cultural-linguistic model is then used in this study and, more specifically, at this stage of the research process, as a theoretical point of departure, which elaborates on our metaphor of narrative in connecting the socio-cultural and historical constructed self-narrative with the narrative of the Bible, thereby extending the continuity of meaning and purpose which might also be embedded within this narrative. It provides us with a framework from which we can view the narratives of the co-researchers, which reflect their understanding and experience of the presence of God, in their specific contexts. Müller (2005:84-85) adds that this movement should be incorporated with the process of social constructionism, as the researcher's understanding of God's presence in a specific situation can also make a valuable contribution.

In accordance with the postfoundational notion of practical theology, various methods in identifying cues which point to a reflection of God's presence, or spiritual and religious aspects, as it is understood in a specific context or situation, were used. The analogue to the life of the biblical figure David was used again as a method in extracting such experiences of and with God.

The narrative of David contains epistemological significance, as one realises that the narrative as it is told in the Bible, is also socio-culturally and historically constructed and acts as an example of a co-constructed narrative, which contains much significance in guiding the lives and practices of the JudeoChristian traditions, even today. However, it still remains a narrative created from a particular perspective, with the aim of serving a particular intention (cf. Brueggemann 2002:ix). The narrative of David, as an analogue to the lives and identity of the co-researchers of this study, contains many contradictions entailed in its initial message which compare with the contradictions experienced by the coresearchers in both their secular and religious lives. Within the person of David, one does not only become aware of the idea that David was a nobody who became a somebody, or a insignificant figure judged too young and too small to reign victory, who, despite of his physical appearance, nevertheless conquered the feared Goliath; within this person there is also a contrasting notion fallibility - of imperfection - of a man who loved God dearly, but nevertheless thought he could hide a horrible sin from God; of a man who could conquer 
the most feared man in the army, but a man who could not conquer his own desires. Despite this, David, still today, embodies the personhood of the man, the male and is seen throughout history to point at the coming of the best Man ever. He is still worthy, despite his sins, because he loved God, and God loved him. This message, applied to the context of this study, revealed the peculiar position in which the boys of this study find themselves.

Additionally, the study investigated the development of faith, religion and a sense of morality pertaining to specifically male adolescence. It was found that the development of religiosity, faith or spirituality is a complex phenomenon that is influenced by various psychosocial events and experiences that a child comes to face during his or her development. In attaining a better understanding the research investigated how religion and identity formation is related. It was found that various aspects influence the formation of an identity, and more specifically a religious identity. Aspects such as religious affiliation and traditions, family relations, gender and race all have a great influence on the formation of a faith or religious identity, thereby also confirming that such an identity develops and is formed within a specific social context and cannot be attributed solely to individual and intrapersonal aspects.

Closely related to the formation of a religious identity, is the development of a sense of responsibility and accountability which is usually visible in the type of, and degree of, roles an individual makes his or her own. Kohlberg $(1969,1980)$ and Kohlberg and Lickona (1976) postulate that the concept of sharing is fundamentally a social concept, which inevitably leads to the development of a social-moral consciousness and which, in turn, involves the idea of role-taking responsibilities. Role-taking responsibilities are many times universal and provide the individual with an opportunity to know who he or she is in relation to others (cf. Balk 1995:185).

The views of James Fowler $(1981,1991)$ were investigated in coming to a better understanding of the development of a person's faith consciousness from childhood to adulthood, where faith does not indicate a specific religious commitment, but is rather a term which indicates '... the universal human quest to identify what is of ultimate value, what gives meaning to existence and what enables a person to be connected to others' (Balk 1995:223).

This study took a closer look at attachment and spiritual development from childhood to adolescence, by referring to various attachment theories. It was found that the attachment of a child towards his or her mother or father plays a particularly big role in the understanding of a child's socio-emotional development which will influence the development of a religious or faith identity and his or her commitment towards a religious body or institution, as faith is both a social and emotional phenomenon. Some scholars have found that infant-caregiver attachment can predict a child's level of empathy, social competence, ego resilience, externalisation and internalisation, and possible behavioural problems later in life (cf. Granqvist \& Dickie 2006:198).
The family as context for religious and spiritual development in children and youth was also investigated. Emerging research has found that children's perception of their parent's beliefs has a greater influence on their own beliefs, than that which their parents proclaim or report to believe. In other words, what parents do or say in terms of religion is less important than what their children think they believe (cf. Boyatzis \& Dollahite 2006:301). It is more about what is modelled to the children and what non-verbal behaviour tells the children, than verbalised information.

Finally, a consideration of the African worldview and its influence on spiritual narratives was needed. The coresearchers of this study stated that they do not partake in any of the rituals or ceremonies related to traditional African religion. This might be attributed to the fusion of culture, language and therefore also religion which takes place in urbanised areas, but perhaps also because of the lack of a consistent caretaker who could instil these traditional values in the lives of these children. Nevertheless, through the sharing of narratives, some reminiscence of traditional African religion did appear.

Upon working with this text, the co-researchers were in agreement that their experience of God was the turning point in their tragic narratives. In the same way that David trusted upon God to save him and be with him during the battle, or when he fought lions and bears, the co-researchers also trust upon God to determine victory over their past. The coresearchers revealed that their communities do not view the expression of your feelings regarding God and your religion as a manly, or masculine. From the discussions it seems that it might be a desire of both men and boys to turn to God when scared or when they experience a storm, but they must either do it in private, or at a faith-based organisation, where it is a requirement to be religious, to be part of the organisation. The boys stated that they live in 'two worlds' - one is in the safe haven of the faith-based organisation (safe house) and the other is in the real world. At both, different rules apply in playing the 'man' game.

It would also seem from these discussions that most, if not all, the co-researchers find their security in their relationship with God. They all tend to see God in terms of motherly characteristics, as someone who protects, who guides and is more powerful than anyone else they know, quite possibly because their mothers also took on the role of a father. It also seems as if all the co-researchers received their religiosity from their mothers, because of a close, secure attachment they had with their mothers. None of the boys had a close secure attachment to their fathers and this might explain why they do not view God much in fatherly terms, or at least in what they have experienced a father to be. They state that God is like a father to them, because God protects and guides and they know that these are qualities expected of an earthly father as well, but their personal experiences have taught them differently. None of the co-researchers have developed a close and loving relationship with either a peer or another significant person; therefore it makes sense that God is now 
the replacement of that secure attachment. It would be interesting to see if they do develop an intimate relationship with another, if their sense of religiosity would increase or decrease. It is important also to note that the guidance they receive from the faith-based and non-governmental organisation has definitely increased their religiosity, but all the care workers from the organisation are female; therefore they, once again, receive spiritual guidance from a motherly figure as opposed to a fatherly figure, thereby reinstating their view of God as a mother.

The lack of a father figure might put them at risk in becoming young fathers as well. It might be true that the religiosity inherited might encourage them to be more involved with their family. All the co-researchers have voiced their need in being a better husband and father than they had, thereby acknowledging the value of a father and a husband in the family. All of the co-researchers also stated that, from a religious point of view, this is what is expected of men from God, as God models the perfect father.

\section{Exploring interdisciplinary meaning}

This requirement applies to the notion of transversality and is concerned with giving a description of experiences, which are thickened through interdisciplinary investigation. It coincides with the sixth movement of a postfoundational practical theology, which is rooted directly in the postfoundational notion of reality. The postfoundational notion of reality states that we have an obligation to move beyond our specific embedded contexts, to cross-cultural and interdisciplinary conversation. It includes the active involvement of other disciplines to assist in the construction of the interpretations of the self-narratives of the co-researchers. This method of inquiry is known as transversality and ensures that the researcher does not impose his or her subjective interpretation on the narratives, so that a holistic understanding can be the end result (cf. Müller 2005:85).

After collecting different views regarding the co-researchers' narratives, the researcher listened carefully to the various narratives of understanding through: the study of related literature, interviews with colleagues and scholars from different disciplines, participatory observation and action in the interdisciplinary field and interviews with care workers from the specific context. Accordingly, an honest effort was made to integrate and assimilate all of these different interpretations so that a more comprehensive understanding could be attained.

As part of the interdisciplinary process, one of the coresearchers provided a short reflection on his experience of the two camps and the group discussions during the camps. This discussion took place on 30 June 2010. His reflection was based on his experience of working with the text and various metaphors, the insights he had gained and the manner in which his experience with this research process motivated him to develop alternative understandings of his own situation.
Additionally, one of the care workers (who is a registered social worker) from one of the non-governmental organisations who did some of the interviews on the researcher's behalf, was also asked to reflect on her experience and understanding of the narratives that she attained from two of the co-researchers. The following questions were posed to her:

- When you listened to Anonymous1's story, what are your concerns regarding him, his familial experiences or experiential context as a social worker?

- When you listened to Anonymous2's story, what are your concerns regarding him, his familial experiences or experiential context as a social worker?

- What do you think is your discipline's (social work) unique perspective on these stories and why is it important that this perspective be heard at the interdisciplinary table (amongst other disciplines such as psychology and theology)?

- Why do you think your perspective will be understood and appreciated by people from other disciplines (such as theology and psychology and maybe anthropology)?

- How did you experience the interview process? Did the boys open up easily or were they hesitant?

- What do you think were the hardest themes for them to discuss?

- From your point of view, how do you think these boys view their masculinity in their community?

- What role models to you think these boys have in being a man in their community or family, if any?

- What do you think are the major consequences of not having a father figure for these boys?

- How do you think these boys view God, similarly and differently?

- Do you think that the absence of a father figure has an influence on their view of and relationship with God? If so, please elaborate.

As mentioned before, the postfoundational notion of transversality motivates us to explore understandings and interpretations beyond the specific and locally embedded context and discipline (in this case practical theology) by engaging in cross-cultural and interdisciplinary conversation. Van Huyssteen (1999) states that:

Transversal rationality thus emerges as a place in time and space where our multiple beliefs and practices, our habits of thought and attitudes, our prejudices and assessments, converge. The texture of this transversality, thus resides in the domain of our social, communal and institutional practices. (p. 136)

Based on this, the study had the imperative to move beyond its own discipline in exploring other rationalities regarding the topic at hand. Four conversationalists from different disciplines - practical theology, pastoral therapy, critical psychology and social work - were invited to engage in interdisciplinary dialogue with the text. A summary of three of the co-researchers' narratives were constructed, with pseudo-names for each co-researcher, and these 
were presented to the conversationalists with the aim of gathering their reflection and/or interpretation of the text at hand. The following three questions were posed to each conversationalist:

- When reading the story of Molimi, Manqoba and $\mathrm{Kgotoso}^{2}$, what do you think would each of their concerns be?

- How would you formulate your discipline's unique perspective on these concerns and why is it important that this perspective be heard at the interdisciplinary table?

- Why do you think your perspective will be understood and appreciated by researchers from other disciplines?

The process was rounded off with a reflection provided by the researcher on the research process, the interdisciplinary process and the value of each scholar's contribution to the understanding of the role that dominant discourses play in the creation of self-narratives and future narratives.

\section{Moving beyond the local}

The seven movements of a postfoundational notion of practical theology were concluded with the development of alternative interpretations, which point beyond the local community. A reflection beyond the local community does not refer to the generalisation of a narrative, but rather to the construction of a narrative that could serve as a meaningmaking resource 'centre', which could be applied to various life experiences - experiences which could happen outside the local community, and which stand in relation to various macro-contexts (cf. Müller 2005:85-86).

Specific techniques and tools were borrowed from the narrative method of doing research and therapy, in unveiling specific unique outcomes, visible through the telling of narratives. These unique outcomes are essential in the development of alternative, non-problem saturated narratives.

The development of an alternative narrative or alternative ways of interpreting past events and experiences did not follow a linear process, but rather circular process where the co-researchers constantly moved between past narratives, the present and then future narratives. The use of the Tree of Life metaphor and the analogue to the life and events of the biblical figure, David, and the various similarities, dissimilarities and interpretations that could be drawn from engaging with these texts, accumulated into the development of an alternative narrative. Movement seven is really the plot of our story and gives way to the development of new perspectives, new understandings and, most importantly, new resources of meaning which could be assigned to past, present and even future narratives.

The Tree of Life metaphor assisted with the deconstruction process of past experiences and interpretations thereof and how this, in turn, influences the construction of a future tree. 2.These pseudo-names were chosen by the co-researchers themselves.
In the drawing of the trees, the co-researchers could look at not only their losses, but also what they gained and how their tree is kept alive through the remembering of their roots and the acknowledgement of what they have or who they are. The Tree of Life metaphor also assisted in the identification of unique outcomes, as the co-researchers realised that they could use their losses positively in nurturing the memories they have regarding the loved ones they have lost. Additionally, the co-researchers could externalise that which they saw as problem-saturated. By externalising their problems or challenges, they could take a step back and see its influence on their lives. They came to realise that to develop a future narrative one cannot ignore or exclude the problem. Rather they should approach their problems from different angles, develop new perspectives on their problems which will liberate them from its deadening influence.

Goldenberg and Goldenberg (2008:365) emphasise the influence of a meaning metaphor by stating that our perceptions regarding our realties are organised and maintained through the stories (and related metaphors) by which we disseminate knowledge and truths regarding our roles and ourselves within the world. Both the metaphor of the Tree of Life and the analogue of the narrative of David served as a meaning metaphor, which could be incorporated within the co-researchers' alternative narratives that enrich the understandings and meanings of their own lives, also because it is seen as embedded within a specific context the context of the world which maintains a tension between the past, present and future narratives of ourselves and our relations with people in these contexts; as well as the context of the story of God, which were made more 'real' and 'relevant' by seeing it in the light of one's own narratives and by realising how God is involved with people whose lives are also embedded and constructed in the human world. Therefore, by using this metaphor and analogue the coresearchers were assisted in thinking about their own lives as stories and experience these stories in a meaningful and fulfilling manner (cf. Freedman \& Combs 1996:1).

The Tree of Life metaphor helped in the construction of a holistic life narrative, where the narrative of David, in turn, showed the socio-cultural and historical constructiveness of our gender-identity narratives. This narrative specifically assisted the co-researchers to reflect on the discourses in the community and to reflect on their future roles, as a possible husband and father. People in our society are not generally encouraged to reflect on such specific roles and the influence the embedded context has in the construction of such narratives. The co-researchers were therefore provided with an opportunity to reflect on how they would like to construct their future narratives, pertaining to the possible roles that they might take in the future, in line with what we learn from the narratives of the Bible.

This narrative also assisted the co-researchers in externalising their problems and challenges in the being of Goliath. By identifying with David, God's chosen one, the co-researchers could see that he also had to face challenges and that he 
also had temptations. This narrative presented the coresearchers with the opportunity to gaze into their own lives, from the perspective of someone who observes the David narratives. The beauty of any narrative is its ability to draw the reader into it and making the reader part of it, because the reader will identify with at least one aspect of the story. This is what the David narrative did for the coresearchers - by identifying with David, if only in one aspect, they could gaze into their own lives, as if from a distance. In creating their own David narrative, with their own Goliath and with their own relationship with God, who has also chosen them for big things to come, they could deconstruct the various 'Bathshebas' who attributed to the writing of their own problem-saturated narratives. In looking at their challenges as battles and the various factors in a battle, they had the opportunity to look at their lives as if a strategy of battle. Therefore, they had an opportunity to understand themselves better and to see the various things that influence their future lives. In essence, the story of David, compared to their lives, empowered them take control of those aspects of their lives where they can make an active decision in taking a preferred direction. Through their own David narrative they could also explore various aspects of their relationship with God; they could determine what role God plays in their lives. This article then concludes with an example of how one of the co-researchers developed his alternative narrative. ${ }^{3}$

\section{An alternative narrative: I am a farmer}

Molimi chose his pseudo-name, meaning farmer, because he is the youngest child in the house, which means that he inherits everything that belonged to his mother. Molimi was extremely close to his mother and in his narratives it seems as if he carries all his mother's dreams and wishes upon himself. Through Molimi's narratives it becomes very clear that his mother's expectations of him were very high, which was not the case for his older brothers. One might conclude from this that Molimi's ability to reflect on his life and his actions is rooted in his desire to make his mother proud. When reading the letter he wrote to his mother, it seems as if he struggles to put his appreciation into words, but that he nevertheless has the highest respect possible for his mother. This respect is also visible in the manner in which he views women. Molimi states that he respects women and that he would aspires to be the best possible husband to his wife one day.

Molimi's narratives clearly indicate the journey that he had to endure since his mother passed away. Molimi and his brothers were left on the streets; they had no home and no one who was prepared to look after him. A non-profit organisation then took Molimi in - here he had the opportunity to live in a safe house, to have food every day and to gain moral support from his newfound house friends and that of the care workers at the organisation. He also received some religious education and guidance and thereby developed a

3.The conversations, poems and narratives presented here were collected from the second Tree of Life camp, 26-28 February 2010, Magaliesburg, Sikelele. His story is published with his permission. closer relationship with God. Everything went well - besides the fact that he mourned the loss of his mother, Molimi was happy. Then Molimi got older and became interested in the music industry as a disk jockey (DJ). His brother introduced him to this context and Molimi received many opportunities to be trained as a DJ. However, with this came along many temptations - he went to clubs at least every weekend; his brother introduced him to alcohol and, to say the least, he made friends with people who had a bad influence on him. Additionally, Molimi had to face the temptation of sexual lust. After a 'mistake' (as he called it) he made at one of the organisation's camps, Molimi was expelled from the safe house and had to live with his brother. At his brother's place, Molimi had to face new challenges - his brother had an alcohol addiction and abused his girlfriend who lived with them, as well as Molimi. This became too much for Molimi to handle and he ran away from home. His brother, overwhelmed with guilt, decided to pay for a place for Molimi to stay. During all this, Molimi never lost his sense of perseverance and received good grades with the aim of going to college. Currently, he is doing very well in school, but reports that he is struggling to maintain his relationship with and commitment to God, as he still face many temptations and challenges.

Molimi, the farmer, as David the Shepherd, never lost sight of God and God's protection over him and his love for him. Molimi does not shy away from proclaiming his love towards God, although he, at times, especially during the second Tree of Life camp, felt a wave of shame over the fact that he gave in to so many temptations. At that stage he felt that he was not leading the life that God wants him to lead. During all of this, Molimi still misses his mother, but one thing that stood out was the fact that he never gave up, he always kept on working hard and he never lost faith in God. At the end, Molimi prospered.

Molimi's journey can be compared to the journey of a farmer (this is the analogue he chose himself to represent the theme of his life story). A farmer is generally someone who is humble, because he is so dependent on God for his prosperity. A farmer has to work physically hard to maintain his land and, at times, must face the worst of hardships when it fails to rain, or when bad weather conditions ruin his crops. However, a farmer is very rarely someone who is not a believer. A farmer is someone who lives close to God, he sees God in all he does, in the growth of his crops and in the times when it rains against all odds. When a farmer does succeed and when his crop prospers, he gives thanks to God, in all humbleness because he is aware of the grace of God that he witnessed every day in his life. At the end, however, no matter how tough the journey was, the farmer always prospers. Therefore, Molimi's alternative story is externalised by this concept of being a 'farmer'.

The journey that leads Molimi to prosper as a farmer is visible through a song he wrote, entitled 'The morning':

I wake up everyday

And I don't feel the morning shine

I took another look into the sky 
Hoping that the sun will shine

And all I feel is the rain

That brings me pain

I kept on praying and praying

Preparing for any pressures of life

Until one day morning

When the rainbow was in the sky

The pain went away and I flew into the sky

I cried tears of joy and I prayed 'Thank you Lord'. (Molimi, Tree of Life Camp 2, 26 February 2010)

Through this song, Molimi explains his journey, the pain he endured and the loss of hope he faced. At the end he was freed from this painful journey (flew into the sky). It is also clear that through this journey he kept on praying, he stayed faithful and hopeful and, at the end, he thanked God for his freedom, thereby acknowledging God's presence in his journey and God's hand of grace in freeing him. Through this song, Molimi already started to develop an alternative interpretation of his past and present narrative. This understanding and meaning developed from not understanding why all of these things happened to him and having no hope for a better future, to gaining understanding, developing meaning and making peace with the past and his circumstances - in being able to move on, having hope again.

Molimi's unique outcome is clear from the African story he wrote, entitled 'Three magical stones':

Long long time ago there was a boy named Molimi. He was a very lonely and sad boy without parents but only a brother was there to support him financially. One day Sunday afternoon he decided to rest a bit and slept. He had a dream and in the dream he was very successful but not rich. He could afford life. In the dream he was visited by the three angels and every angel gave him a wish stone.

The first stone he wished that his parents were alive and they were staying together. The second stone he wished that he had all the riches in the world. The third stone he wished that he was the best DJ in the whole wide world. Everything was the way he wanted. He lives all his life with everything he wanted.

Until one day his parents had to divorce, everybody wanted all the money he had and his wife gave him HIV/Aids. The phone ringed in his dream and that was an alarm waking him up. He woke up realising that it was all a dream. So he started to take life as it is and stop blaming God for taking his parents. He started to work his way up and focus on God. (Molimi, Tree of Life Camp 2, 27 February 2010)

In this story, Molimi's understanding of his misfortunes is described. He states that he was lonely and sad, because he had no parents and he had no money. Then he had a dream - this dream might indicate the journey had had to take before arriving at the plot of his story where he realises that he cannot change anything and that he does not have the wisdom in determining what would have been better. His statement of '... very successful but not rich', corresponds with Molimi's former narratives where he stated that he does not want to be rich, he just wants to get by, the love in a family is more important to him than the money he has. This indicates a mature and humble attitude, which reminds one of the attitudes of a farmer, where he realises, in facing God's grace and God's glory, that money cannot bring happiness. This story also indicates Molimi's awareness of the heartache in life, where greed ruins relationships and where people are affected and infected with HIV and AIDS. This story indicates that Molimi has moved from experiencing hardships and illness, to understanding the causes and the consequences of these hardships and illness. When moving from experience to understanding, a person is changed inside. This change results in a person adapting - a change in the cognitive, the affective and, consequently, in behaviour reveals an acceptance of one's circumstances. Understanding also indicates a sense of responsibility and accountability; where experience leaves one to the mercy of fate, understanding takes one out of the helpless position, to a position where one is in control, where one has hope, because one understands the dynamics of life, where blaming makes one a victim, but taking responsibility makes one a victor. This understanding inevitably changes one's future narrative.

The turn of Molimi's narrative took place when he 'woke up realising that it was all a dream'. His alternative interpretation, in turn, is summarised in two sentences: 'So he started to take life as it is and stop blaming God for taking his parents. He started to work his way up and focus on God.' In these two sentences much is said. Firstly, Molimi accepted his fate, accepted his life and started to look forward and live his life. He made peace with God and peace with his fate. He changed his former interpretation of 'God punished me by taking my parents away', to 'God is not at fault'. In Molimi's letter to his mother he said that 'God has chosen you [his mother]', perhaps indicating that God has not 'taken', but 'chosen'. The word 'chosen' has a much more positive connotation, indicating a privileged position. It is always a privilege to be chosen, where 'taken', in turn, indicates force, against one's will and a helpless position. In the narrative of David (1 Sm 18:2) we read that 'Saul took him [David] that day and would not let him return to his father's house' (Hamilton 2008:260-261). David was taken unlawfully and Molimi thought God had taken his mother too, unlawfully. But where David has been chosen by God (1 Sm 16) he has also been taken, but with a glorified goal in mind. In the same way, Molimi can indicate through his word play of 'chosen' versus 'taken', that he has now come to understand that his mother too has been chosen, with a glorified goal in mind.

By externalising the concept of father into the concept of farmer, Molimi indicated that, for him, a father is like a farmer. Molimi never spoke of his father and always referred to his big brother when referring to a significant male figure in his life. However, his lack in a father figure does not seem to influence his view of God. It seems as if God, for Molimi, is a Farmer. It is clear from Molimi's final narrative that, for him, God is provider and protector. Molimi does not see or seek God as a 'quick fix'. Molimi does not only turn to God when in need. Molimi moves and God moves with him, beside him. For Molimi, God nurtures, God endures, God does not reveal himself quickly, but takes his time, just as crops takes time to grow, waiting for the precise right time 
to harvest. It is almost as if Molimi is the crop and God is the Farmer. And at the end of the journey, where Molimi, as the crop, endured much pain and suffering, where Molimi felt alone during the storms and during the drought, he came out fresh and stronger than ever, ready to be harvested. Therefore, Molimi's view of God does not seem to be as much connected to gender and modelling, than to office and experience. Molimi's alternative narrative is, in essence, created as a result of his journey with God, much like a farmer's journey with his crop.

\section{Conclusion}

The above alternative narrative illustrates how the process of a postfoundational notion of practical theology leads us not only to describe the context, but also to understand the underlying experiences that happen in the specific and local context. It shows the importance of understanding that meaning is created from within a specific local context, in interaction with our social world and understood from our specific cultural and traditional values. As Christians, meaning is furthermore enriched by the way we understand and experience God in our concrete and social contexts. By delving into our rich interdisciplinary resources, we are offered an opportunity to understand different perspectives of a specific phenomenon, which will not only increase our understanding of the dynamics of a phenomenon, but will also supply our co-researchers with a multitude of options to create future narratives which will liberate them from the constrains of a narrowly defined and one-dimensional problem-saturated narrative.

\section{Acknowledgements Competing interests}

The author declares that she has no financial or personal relationships that may have inappropriately influenced her in writing this article.

\section{References}

Boyatzis, C.J. \& Dollahite, D.C., 2006, 'The family as context for religious and spiritual development in children and youth', in E.C. Roehlkepartain, P.E. King, L. Wagener \& P.L. Benson (eds.), The handbook of spiritual development in childhood and in adolescence, pp. 297-309, Sage Publications, Thousand Oaks.

Browning, D.S., 1991, A fundamental practical theology, Fortress Press, Minneapolis.

Brueggemann, W., 2002, David's truth in Israel's imagination and memory, 2nd edn., Fortress Press, Minneapolis.

Demasure, K. \& Müller, J.C., 2006, 'Perspectives in support of the narrative turn in pastoral care', Nederduitse Gereformeerde Teologiese Tydskrif 47(3), 410-419.

Erikson, E.H., 1998, The life cycle completed, Norton, New York.

Fowler, J.W., 1981, Stages of faith: The psychology of human development and the quest for meaning, Harper San Francisco, San Francisco.
Fowler, J.W., 1991, 'Stages of faith consciousness', in F.K. Oser \& G. Scarlett (eds.), Religious development in childhood and adolescence, pp. 27-45, Jossey-Bass, San Francisco.

Freedman, J. \& Combs, G., 1996, Narrative therapy: The social construction of preferred realities, W.W. Norton \& Company, New York.

Ganzevoort, R., 2012, 'Narrative approaches', in B.J. Miller-McLemore (ed.), The Wiley-Blackwell companion to practical theology, pp. 214-223, Wiley-Blackwell, Chichester.

Geertz, C., 1991, The interpretation of cultures: Selected essays, Fontana, London.

Gerkin, C.V., 1991, Prophetic pastoral practice, Abingdon Press, Nashville.

Goldenberg, H. \& Goldenberg, I., 2008, Family therapy: An overview, Thomson Brooks, Toronto.

Granqvist, P. \& Dickie, J.R., 2006, 'Attachment and spiritual development in childhood and adolescence', in E.C. Roehlkepartain, P.E. King, L. Wagener \& P.L. Benson (eds.), The handbook of spiritual development in childhood and in adolescence, (eds.), The handbook of spiritual development
pp. 197-210, Sage Publications, Thousand Oaks.

Hamilton, V., 2008, Handbook on the historical books, Baker Academic, Grand Rapids.

Holborn, L. \& Eddy, G., 2011, First steps to healing the South African family, South African Institute of Race Relations, Johannesburg.

Joint United Nations Programme on HIV and AIDS (UNAIDS), 2010, Report on the global Aids epidemic, WHO Library Cataloguing-in-Publication Data, viewed 06 May 2013, from http://www.unaids.org/globalreport/Global_report.htm

Kohlberg, L., 1969, 'Stage and sequence: The cognitive-developmental approach to socialization', in D.A. Goslin (ed.), The handbook of socialization theory and research, pp. 347-480, Rand McNally, Chicago.

Kohlberg, L., 1980, 'High school democracy and educating for a just society', in R.L. Mosher (ed.), Moral education: A first generation ofresearch and development, pp. 20-57, Praeger, New York.

Kohlberg, L. \& Lickona, T. (eds.), 1976, 'Moral stages and moralization: The cognitivedevelopmental approach', Moral development and behavior: Theory, research and social issues, Rinehart and Winston, Holt.

Lindbeck, G.A., 1984, The nature of doctrine: Religion and theology in a postliberal age, Westminster Press, Philadelphia.

Loubser, J. \& Müller, J.C., 2011, 'The use of metaphors in narrative research in exploring and describing the experiences of adolescent male orphans affected by HIV and AIDS', HTS Teologiese Studies/Theological Studies (67)2, 9 pages. http:// dx.doi.org/10.4102/hts.v67i2.1009

Marcia, J.E., 1993, 'The ego identity status approach to ego identity', in J.E. Marcia A.S. Waterman, S.L. Matteson \& J.L. Orlofsky (eds.), Ego identity: A handbook for psychosocial research, pp. 3-21, Springer-Verlag, New York. http://dx.doi. org/10.1007/978-1-4613-8330-7 1

Monama, T., 2012, 'Sharp rise in fatherless kids', The Sowetan, 18 December 2012 viewed 08 May 2013, from http://www.sowetanlive.co.za/news/2012/12/18/ sharp-rise-in-fatherless-kids

Müller, J.C., 2005, 'A postfoundationalist, HIV-positive practical theology', Practical Theology in South Africa 20(2), 72-88.

Pattison, S., 2000, 'Some straw for the bricks: A basic introduction to theological reflection', in J. Woodward \& S. Pattison (eds.), The Blackwell reader in pastoral and practical theology, n.p., John Wiley and Sons, New York.

Pretorius, J.W.M., 2009, Sociopedagogics 2000, 4th edn., Van Schaik Academic, Pretoria.

Schrag, C.O., 1992, The resources of rationality: A response to the postmodern challenge, Indiana University Press, Bloomington.

Thrift, E. \& Amundson, N., 2007, 'Shaping the story: A guide to facilitating narrative counselling', in K. Maree (ed.), Theoretical underpinning and practical application of hermeneutic-narrative approach to career counselling, pp. 39-50, Van Schaik of hermeneutic-narrati
Publishers, Pretoria.

Van Huyssteen, J.W., 1997, Essays in postfoundationalist theology, Eerdmans Publishing Company, Grand Rapids.

Van Huyssteen, J.W., 1999, The shaping of rationality: Towards interdisciplinarity in theology and science, Eerdmans Publishing Company, Grand Rapids. PMid:10615973

Van Huyssteen, J.W., 2004, 'Postfoundationalist rationality', Unpublished lecture prepared to be used as the first Gifford Lecture, University of Edinburgh, Scotland.

Welsch, R.L., 1998, An American anthropologist in Melanesia: A.B. Lewis and the Joseph N. Field expedition, 1909-1913, 2 vols., University of Hawaii Press, Honolulu.

Willows, D. \& Swinton, J., 2000, 'Spiritual dimensions of pastoral care: Practical theology in a multidisciplinary context', in J. Woodward \& S. Pattison (eds.), The Blackwell reader in pastoral and practical theology, n.p., John Wiley and Sons, New York. 